\title{
MANAGERIAL CHALLENGES IN RUSSIAN RAILWAYS PRIVATIZATION AND RESTRUCTURING IN THE CONTEXT OF INTEGRATION INTO GLOBAL TRANSPORT SYSTEMS
}

\author{
Natalia Aleksandrovna Zhuravleva ${ }^{1, a,{ }^{*}}$ \\ ${ }^{1}$ Emperor Alexander I St. Petersburg State Transport University, 9 Moskovsky pr., Saint \\ Petersburg, 190031, Russian Federation \\ azhuravleva_na@mail.ru \\ *Corresponding author
}

Cite as: Zhuravleva, N.A. (2017). Managerial challenges in Russian railways privatization and restructuring in the context of integration into global transport systems, Ekonomicko-manazerske spektrum, 11(2), 122-133.

Available at: dx.doi.org/10.26552/ems.2017.2.122-133

\begin{abstract}
The article describes the results of an analysis of the processes of privatization and the restructuring of railways, in the context of their inclusion in international transport projects in managerial perspective. The purpose of this study is to emphasize the totality of the rational property relationships, interrelationships and the competition between their structural elements in present-day railway transport systems, and also the influences of branch restructuring on the market effectiveness of transport services. The methodology used in this study involved building on a structural-functional approach and emphasizing the totality of the steady relationships and interrelationships between their elements and their roles relative to each other and to the global market, for the transport services as a whole in the integral transport systems. The processes involved in the optimal model formation of the industry structure were studied. The following structural elements, which are basic for evaluating the expediency of railway privatization, were evaluated: the organizational form of the business, market competition and the separation of the infrastructure and transportation functions. A conclusion was made about the absence of a connection between the structural business model and the privatization effects; namely, the investment needs of the railway infrastructure are considerably higher than the amount that is invested, the active railway memberships are evaluated based on this and the asymmetry prevents the flow of the investments necessary for the branch. The effects of an increase in the market competition in different organizational models of the market for rail transportation were also studied. As a result, a conclusion was made about the reasons for the absence of such an effect on the Russian rail freight market. In the study, it is assumed that the conclusions will be applied to the current processes of the Russian railways privatization and restructuring as a part of the Eurasian transport system infrastructure. It was proven that the basic effects of privatization and restructuring were a result of the density of the network, the openness of the market for transportation and the effectiveness of the national railways controls. It was substantiated that it is precisely the globalization of the economy that ensures the threedimensional effectiveness of global transport systems, drawing in investments through their development and improving the quality of transport services for the users.
\end{abstract}

Keywords: privatization, restructuring, investment, effectiveness of the transport market

JEL Classification: F600, R400 


\section{Introduction}

The integration of Russian railways into the Eurasian transport systems is one of the major steps in the development of the transport business and the formation of an effective national transport infrastructure. The open joint stock company "Russian Railways", as a state company, still has a monopoly on the entire railway infrastructure in terms of its general use and locomotive improvements. The further development of the company is connected, first of all, with its inclusion in international transport corridors. The business restructuring of the open joint stock company "RR" and the possibility of its partial privatization will make it possible for it to draw nearer to the status of a public and intelligible player, in which the solutions are transparent and the methods of control are targeted at the user - the consignor or passenger. Moreover, the public status of the company will be an additional tool in the control over the decision making process. A study of the problems and consequences of the privatization and restructuring of national railways is extremely urgent for the development of global transport systems, since it is precisely these that must become the infrastructure for the new technological wave that is forming in the world. The global transport systems, in their turn, will be subjected to the influence of fundamental changes in transport services related to the changing requirements in terms of their quality, their new geography and even the very essence of the transport service, in which speed and spatial effectiveness will become the first key elements. (Mwase, 2003; Wolf, 2017) First of all, as global transport systems, we understand these to include the connectedness of the various modes of the transport infrastructure, the transportation and logistics organizations and the rules of the state regulations in interstate agreements, which ensure the efficient movements of passengers and goods and are aimed at enhancing security, competitiveness and accelerating the economic development. (Zhuravleva \& Panichev, 2016) In its essence, privatization is a special system of economic relationship, which appears in connection with a change in the form of the property: from "state" to "private". The processes of the structural changes in a branch accompany the issue of rail transport privatization. Similarly, the system changes will significantly affect the rational functioning of the global transport systems. When it comes to infrastructural companies, one of which is the open joint stock company "RR", the theory of privatization makes it possible to estimate the risks and effects of the commercialization of the transport business, as well as the methodology of the structural reformation in the market for rail transportation and therefore, the required level of competition in this market can be supported with these facts. (Lust, 2017; Pendleton, 2003)

The history of the privatization and restructuring of railways goes back decades and is connected with the global processes that can be observed in the world economy: an increase in the competition among national and global markets for goods and technologies; and the change of the technological structure, which has led to the appearance of a high-speed, intellectual infrastructure. Worldwide competition contributes to the arrival of new, alternative integrative transport projects, each of which is characterized by a large scale and ambition. This refers to the Trans-Pacific Partnership, the Economic Belt of the New Silk Road (One Belt, One Road) and the possible Transatlantic Partnership. The likely success of these international projects will allow the countries participating in their implementation to obtain additional economic advantages, in the form of attracting financial support for the infrastructures in their own territories, which will positively affect their trade balances. (Pelaez \& Sanchez-Cabezudo, 2010; McCartney \& Stittle, 2008) The problem of the harmonization of national transport systems in a single international transport system in the EAEU area is becoming extremely relevant, including the correspondence of the national functional structures with regard to the forms of international business. The purpose of this study is to emphasize the totality of the 
rational property relationships, interrelationships and the competition between their structural elements in the present-day railway transport systems, and also to explore the influences of branch restructuring on the effectiveness of the market for transport services. It is assumed that the conclusions of the study will be applicable to the current processes of the privatization and restructuring of Russian railways, as one of the infrastructural elements of the Eurasian transport system. The work was formed on the basis of a desk study that included: a content analysis of key program documents about the development of the transport system of the Russian Federation, reports, memoranda, intergovernmental agreements about the development of international transnational designs, instant analyses and expert reports on the problems and consequences of the privatization of railways, reports and materials of the open joint stock company "RR" and the joint stock company "Institute of Economy and Transport Development", as well as reports and contributions to the international congresses and forums held from 2009-2016.

\section{Literature review}

In any form of privatization, the policies must appeal, first and foremost, to the political decisions, followed by the economic interests and their justifications. The political conditions leading to privatization stem from profound problems in the influence of the state-owned companies on economic growth, based on the investment climate of a given national economy. (Evans, 2013; Asquer, 2011) This has a direct bearing on the privatization of the state-owned infrastructure facilities. In most cases, these processes are considered as activators of the development of transport systems. Cavaliere and Scabrosetti (2008) define two directions for the development of a privatization policy. In the first one, the effectiveness of the management of the government and the private agents acquiring the property as a result of the privatization are compared. In the second approach, the question of whether the privatization will lead to restructuring is examined. The first direction, which was more widely considered by Sappington and Stiglitz (1987), shows that the form of ownership is not essential if one assumes the symmetry of information, the neutrality of the agents to risk and perfect competition among the private agents for state-sold property (the Sappington-Stiglitz theorem). If these conditions are not met, then privatization does not necessarily lead to an effective solution. In particular, if risk aversion is typical for the private agents (which is quite likely), and the production risks are high, then the privatization will not provide efficiency. The connections between employment, restructuring and privatization - which is the prevailing theme within the framework of the second direction - asserts that the decision on the privatization involves a trade-off between the politicians and the managers (the Shapiro and Willig model, 1990).

In a number of works, and in particular those by Boardman et al. (2002), it is asserted that the profitableness of a business grows after privatization, while the productivity and payments of its dividends increase, and the debt load decreases. Kole and Mulherin (1997) present an extensive sample analysis of the privatization of enterprises in the USA, on the basis of which they reached the conclusion that there is no difference in the effectiveness of state and private enterprises. Meanwhile, Villalonga (2000) gave a list of more than 150 works, where the effectiveness of privatization was compared. This review showed that 75 per cent of the works referred to by the author confirmed the efficiency of private enterprises; while one third of the authors contended that there was no basis for this conclusion. At the same time, an analysis of the efficiency of the privatization of 24 Spanish companies, on the basis of data that was collected over a number of years, did not support the hypothesis of the positive effect of privatization, since its results were influenced by national institutional and organizational 
factors. One of the main objectives of privatization, which is namely a significant increase in the investment per unit of sales, is not achieved based on the study results by Boardman, Laurin and Vining (2002), and the study by D'Souza and Megginson (1999). Furthermore, Straska and Waller (2012) argue that after the privatization, the investment activities of a company will fall. The authors considered a selected subset of 63 large American companies, whose shares were sold from 1980-2007, and confirmed the increase in the relative debt (leverage) after the privatization. Unfortunately, in none of those works is an increase in the total factor productivity (TFP) after privatization fixed.

However, positive examples should be noted of the impact of the synergy of privatization decisions on an improvement in the investment climate and the maintenance of high rates of economic growth under the influence of the globalization of the economy. This has been confirmed by a thematic analysis of 13 economies, whose growth was at the level of $7 \%$ from 1975 to 2008, which was carried out by the World Bank. It was alleged that this growth is due to macroeconomic management supported the domestic capital markets, which provides a high level of domestic savings and investments that usually exceed 25 percent of the GDP (The Report Strategies for Sustained Growth and Inclusive Development, 2009). Shavshukov (2016) asserts that the growth of the developing countries, for example BRICS, is connected with the fact that these countries have invested in technology and knowledge, and have imported production processes and goods. Thus, a study of the empirical works focusing on the estimation of the effectiveness of privatization reveals that the roles of the increase in the investment activity, the decrease of debt, and the influence of privatization on the economic increase cannot be evaluated unambiguously. (Evans, 2010; Tovar \& Martin-Cejas, 2010) The decisions to privatize individual industries and activities, by themselves, have no direct correlation with the activation of the investment climate and the effectiveness of companies. Therefore, the effects of this process should rather be sought in terms of the growth of the government's efficiency index and its involvement in global technological and infrastructure projects. (Baaj, 2002; Parker, 2013) That is why the issues related to privatization have recently been experiencing a constant movement: from being the top-priority, to being politically irrelevant, and vice versa. (Kessides, 2005) There is one important circumstance that determines the political moment that marks the beginning and the activation of privatization - this is the period of time during which the national economy is finding the best conditions for attracting domestic and foreign investments. The coincidence between the implementation of the decisions on the privatization of state property and a significant improvement in the investment climate is the main rule in the expectation for a successful privatization. (Taylor, 2004) At the same time, one should not underestimate the influence of the individual processes that accompany privatization. In particular, during privatization, investors often "intensify" the acceleration of structural and legislative reforms, primarily in terms of strengthening property rights and competition. The realization of the investors' interests can also have an influence on the effective containment of corruption.

\section{Economic feasibility of railway restructuring under various industry models}

A generalized model of the railway industry, which existed as the dominant one up to the 1970s as the traditional railway, included the following main characteristics:

- $100 \%$ state ownership;

- functioned as a Ministry (for example, the Ministry of Railways of the RF), a Department of the Ministry or a government agency subordinated to the Ministry; 
- implemented passenger and freight traffic within a single structure;

- a vertically integrated management system for the railway and transportation infrastructure was available;

- a number of activities that were non-core for the railway were available.

In the last decade of the 20 century, several innovative structural elements of the modern railway industry were shaped, namely:

Complete separation: This means a full legal, organizational and institutional separation, where an infrastructure management company provides infrastructure services to the transport carriers on the basis of a contract; for example, Railtrack in the United Kingdom.

Partial separation: This means a legal and organizational unbundling of the infrastructure company and the carrier, but where the transport carrier is nonetheless responsible for the main functions of the infrastructure management. An example of a partial separation can be observed in the French railway industry, in which the infrastructure company RFF and the carrier - the incumbent SNCF - are completely separated, but some kinds of activities related to the infrastructure management are carried out under a contract by SNCF. In particular, SNCF is responsible for the maintenance and operation of the rail network and the provision of information to the authority responsible for scheduling (Direction de Circulation Ferroviaire).

Partial integration: In this case, the infrastructure company and the carrier are organizationally separate, but are part of a single holding company. As they have common strategic and commercial objectives, they will most likely seek to monopolize the market. Thus, there are more opportunities for effective coordination between the work of the infrastructure company and that of the carrier, respectively. In some countries, where the railway industry is partially integrated, the level of openness of the market is very low (for example, Germany and Italy).

Complete integration: In this case, there is no separation between the infrastructure company and the carrier, and a vertically integrated company performs the functions of both (for example, the Russian railways). This structure is the least "transparent" one and it generally does not provide opportunities for competition; however, it is effective from the point of view of railway transport coordination.

Despite the fact that full integration (where there is no separation between the carrier and the determination of an equitable, non-discriminatory access to the infrastructure) is currently prohibited by EU legislation, 20 of the 26 European countries with a well-developed railway infrastructure have an integrated or a partially integrated structure. Often, after announcing the complete or partial separation of the railway infrastructure from the transportation activities, the railway administrations actually remain partially integrated, which indicates that a formal approach to the requirement of independence is required and that there is reluctance to apply the separation in practice. Often, this is due to the fact that rail transport, and in particular the infrastructure, requires coordination. Inconsistency between the work of the railway infrastructure and the transportation activities usually leads to additional transactional costs. It should also be borne in mind that the level of coordination depends on the condition of the railways: railways requiring changes (updates, improvements, extensions), will have a greater need for coordination than railways that are in a stable condition (with low a demand for the condition changes and a stable infrastructure topology). The problem of the coordination and harmonization of mixed type transportation (intermodal and multimodal) in the global transport system remains the most important, and this is in turn is reflected in the processes involved in the privatization of railways as a general tendency.

Studies show that a state enterprise reflects the high degree of politicization of the railway and the weak potential of the state administration due to the fact that the budgetary support is 
not structured and forecasted. A company with the principal participation of the state carries the same problems as a state enterprise, but in this case, the state has a higher degree of willingness and the ability to form contained contractual arrangements for the support and development of the railway industry. A private company is able to maintain profitable economic activities; whereas the state must accept the market conditions in determining the balance between its offered prices and services. The search for the optimal structure of railway transport organizations cannot be considered as complete. The formation of the optimum model of the industry structure, or in other words the most effective combination of state and private property (a governmental unit enterprise, state company or a particular company), which should be utilized in the new technological structure and in global transport systems, remains the most important task in its development. The analysis of the existing models of railway industry cannot be completed without a study of the influence of the restructuring of railways throughout the world on the effectiveness of the transport markets and the quality of the rail transportation services from the perspective of an increase in the industry's competitive ability. According to the basic economic theory of supply and demand, an increase in the quality of the transportation services in the transport market is ensured by competition in that market. Competition creates an inducement for guaranteeing the satisfaction of the market needs at a rock bottom price and it provides a stimulus to introduce innovations and obtain market advantages. The strongest arguments in favor of competition in the transport market have characterized the railway freight traffic industry, which has been privatized first of all in the process of railway restructuring. Even in some of the small markets for rail transportation in particular countries of Europe and the states of Australia, the competition in the sphere of railway freight traffic has been significant and effective. Competition in rail freight traffic as a consequence of the restructuring of the state railway companies is present in approximately 30 countries around the world, and it exists in three major institutional structures:

- Competition among the operators of the vertically-integrated railway routes, in accordance with the treaties for the right of access to the railway lines at concrete points and with the particular agreements between the railway companies (for example, in the USA).

- Competition between the operators who have the required, but limited, rights of access to the infrastructure, as is determined by the national legislation. These access rights are limited to certain routes and/or circumstances and they exist in Canada, Brazil, Mexico and the Russian Federation (with regard to the operators of freight wagons);

- Competition between the operators on the basis of their common access rights, with the mandated policy of expanding access to the public infrastructure networks, as for example, in the countries of the European Union and in Australia.

These three models ensure a number of effective tools that allow the independent private companies, which are responsible for the operation of the freight trains, to use the national railway networks and to ensure coordination of the operations in the presence of several operators.In contrast to this, competition among the suppliers of the passenger rail transportation services is encountered rarely (in essence, only in the European Union countries), and it is achieved within the framework of the following three scenarios:

- between the national operator of the transportation over large distances and the operator of the regional transportation networks on the separate routes (for example, the inter-city express trains (ICE) on the railways of Germany and the concessionaires on the regional routes);

- between two operators on parallel or partially coinciding routes (for example, 10-20\% of the market in the United Kingdom); 
- access to the railway lines by third parties (there are several companies in the UK, and the introduction of such a transportation system is planned between Cologne and Hamburg, which will comprise competition to the national railways of Germany).

Consequently, the following three structural elements - the organizational form of the business, the market competition and the efficiency of the separation - are the basis for evaluating the expediency of railway privatization.

\section{Privatization of the Russian railways in the context of the development of international transport systems}

Since the establishment of "Russian Railways" in the year 2003 to now, the railway industry in the Russian Federation has been in the process of reforming and implementing the partial privatization of certain types of business. By analyzing the data regarding the results of these processes, let us estimate two basic positions: the privatization policies and the methodology of the reformation. First of all, the structural reform of rail transport in Russia, as in the majority of similar reforms around the world, has basically proclaimed an increase in the quality and a reduction in the cost of the rail transportation service. Besides the quality of the maintenance, it is understood that this means an increase in the velocity, safety and accessibility of the transportation service. The most representative example is cargo rail transportation, in which the privatization of part of the operating railway cars started in the year 2010. In the same period, the appearance of a competitive market for freight railway car operators was indicated. Two or three years after the reform, their number on the market grew to 10s of thousands of companies. As a result of this competition, the portion of the railway carriage component in the transportation tariff has been reduced twice. However, it subsequently became obvious that the imbalance between the highly-competitive market for operating the railway cars and the infrastructure and the locomotive development was being monopolized within the framework of the open joint stock company "RR". The state company, as a result of having serious problems with its quality and the limitations of its infrastructure and trust, could not stop an increase in its operational expenses and it experienced serious problems in terms of attracting investments. Thereafter, problems with the market regulation and traffic management became apparent. During this period, the carrying capacity of the railways has been seriously decreased due to the accumulation of idle railway cars in the network waiting for incoming cargo, as well as the traffic composed of a large number of empty railway cars. The ineffectiveness of the competition has been officially explained by the effects of the scale of the Russian railway network. This fairly common opinion has triggered a market reduction to 10-15 major operators, and has actually created monopolies for certain modes of transport. The reduced competition has allowed for a partial stabilization of the transportation process, but as a result, it has led to an increase in the transportation costs and shortages of certain types of railway cars. We can affirm that such results of the reform are not related to the level of the competition in the transportation market. Regardless of which company performs the carriage, a larger volume is associated with lower costs per infrastructural unit. That is, a large part of the so-called economy of scale actually represents a savings that happens due to the increase in the density achieved by reducing the average unit cost for the additional traffic within a fixed railway infrastructure. The second basic purpose of the privatization of the railways - namely, the attraction of investments in the development of the infrastructure - has also not been realized in the process of the structural reform. Today, the level of the development of the rail transport system directly depends on the volume of the state subsidies and investments. Despite the fact that, apart from the freight railway cars, the car-repair companies and non-specialized forms of 
business were privatized, the passenger transportation of suburban and long-distance lines were separated into subsidiary companies, and 123 subsidiary and associated companies were established, the main company has not succeeded in attracting significant investments for its development. Throughout the entire reform period, the possibility of privatizing a 5\% stake in the open joint stock company "RR" was discussed, but this decision was postponed due to the company's insufficient capital and its low attractiveness for investors. However, it should be noted that the privatizing of such a naturally monopolized sector of the economy, such as is the case of the Russian railways, is a non-standard task. The decision is connected to the fact that the open joint stock company "RR", like all railway companies that were established with the participation of the state (state-established companies, or SEC), has in addition to its own rating regarding the creditworthiness of the company (stand-alone credit profile, or SACP), sovereign ratings which reflect the assessed potential for government support. In particular, the Standard $\&$ Poor's Ratings Services will give a CCC+ sovereign rating to a railway company in the case of an almost unconditional probability of state support, while in urgent cases it will increase the rating to $\mathrm{BBB}+$, and in the case of the probability of a high level of support the rating rises to $\mathrm{B}+$. This is due to the fact that a default of the SEC can have serious consequences for the state for a number of reasons. In particular, the SEC plays a very important role in solving key economic, social and even political tasks of the government. On the other hand, if the SEC is a restructured company it is operating in the conditions of competition, i.e. its default or a sharp weakening of its solvency can destroy the activities of other organizations and have a significant economic impact on the country or region. The government of the Russian Federation, being the sole shareholder of OJSC «Russian Railways» and rending an extremely high level of support to the company, has thereby increasing its own ratings in terms of the rating agencies as follows: Standard \& Poor's (BB +) and Moody's (Ba1) (stable). (Russian Railways, 2017) Typically, the investor always takes into account the government's influence on the valuation of a privatized company. Another circumstance that is taken into account by investors is connected with the fact that the rate of the investment will also be significantly affected by the competition for capital in the domestic and foreign markets. The current domestic political and circumstances, in which external (sanction) activities have had an effect on the Russian economy, complicate the attraction of investments and are losing in the competition market for capital. This is the main environment in which the decisions about the privatization of rail transport in Russia are being discussed. Obviously, given such economic conditions, it is possible to make political decisions about the privatization of large state properties only after very weighty arguments. These arguments are also connected with the entry of the Russian railways into the global transport systems. This occurrence is accompanied by the emergence of new transnational transport projects that are expanding the geography of the global commodity markets, increasing the efficiency of the spatial transport networks and improving the economy of the national transportation systems. It follows that, despite the negative impact of the current capital structure, and the liquidity and attractiveness of the shares of Russian Railways or its subsidiaries to the market investor, there may be confirmed interest from strategic investors that can pay a bonus on top of the market quotations for the participation of Russia in the international transport networks.

\section{Discussion}

The main reasons and the institutional basis for the privatization of railways, which started in the UK, are described in sufficient detail in the scientific literature. In particular, Gibb, Lowndes and Charlton pointed out that the privatization of public-sector industries has been a 
key policy of the UK Conservative government ever since the 1979 general election. In addition to the public utilities such as gas, electricity and water, the transport industry has experienced massive restructuring in the form of privatization and deregulations that are intended to promote competition and engender a more flexible market place, and the authors examine the privatization of British Rail to evaluate the changing policy objectives and the potential impacts of rail privatization. (Gibb et al., 1996)

An important analysis and an impact assessment of the privatization of the British railways was carried out by Pollitt and Smith. These authors pointed out that major efficiencies have been achieved and the consumers have benefited through lower prices, whilst the increased government subsidies have been largely recouped through the privatization proceeds. They found that a privatized structure, where the shareholders demand a return on their investment, has led to significant improvements in the operating efficiency. (Pollitt \& Smith, 2002) Nonetheless, Thompson noted that changes in the ownership structure are being explored, ranging from allowing some private operators to use public facilities - and public operators to use private facilities - to outright privatization. In all of these cases, concomitant changes, particularly labor restructuring, are emerging as critical factors. Therefore, although there is no fixed recipe for success, the issues are beginning to be better understood and useful alternative approaches are emerging that could improve, but which do not guarantee, the chances of the survival of the railway modes. (Thompson, 2003) Estache et al. (2002) conducted a study with regard to the railways of developing countries. The authors noted that railway restructuring and privatization have now become a mainstream policy option in many developing countries. This paper provides the first analysis of the efficiency payoffs for the railway reforms in two developing countries, Argentina and Brazil. The evolution of the performance of the private operators in both countries since reform was tracked by comparing it with the pre-reform performance whenever possible, as well as by distinguishing between the output and input sources of the efficiency changes. This was done by computing the total productivity factor of each business unit since the regulators were able to start collecting enough data.

An investigation into what went wrong and why, finding that several factors were involved, including the objectives that the new processes were expected to meet and the software that was being developed to support these new processes, were the issues analyzed by Watson. This author offers clear lessons to be learned from the UK experience that should inform the debate on future railway restructuring initiatives. (Watson, 2001) The economic aspects of privatization, and in particular the strategy of transaction costs for privatized railways in the UK, were considered by Shaoul (2006). This author produces evidence that shows that in the UK, the rail industry's costs have more than doubled since privatization began (from $3.4 \mathrm{bn}$ pounds in the last year before the restructuring of the industry to 7.4 bn pounds in 2003), partly because of the 800 million pounds that have been returned to the finance providers. This constitutes more than one-thirds of the rising annual subsidies, which raised important questions regarding the accountability of public money, where the reporting is far from clear. The study also reveals how hard it is to get reliable information about the rail industry's subsidies and expresses a concern that the reporting of billions of pounds of taxpayers' money and the potential liabilities and future commitments are so opaque.

The risks for the privatization of railways for freight transport were further considered by Pittman (2011). This author suggests that the government consideration of serious structural reforms has given way to an emphasis on dramatic expansions of the track network, most conspicuously through the construction of high-speed passenger lines to free up the capacity for freight trains. However, a good deal of uncertainty remains both as to whether there will be a sufficient track capacity to handle the increased volumes of coal and containers necessary for 
this continued growth, and whether the desired private investment funds will be forthcoming so long as the system remains under tight government control. A comparative analysis of the restructuring of the railways in Russia and in the countries of Central and Eastern Europe has been conducted by a number of authors, such as the study by Friebel et al. (2007) which shows that there are some improvements in productivity associated with the reforms in the European Union (among others, access to the infrastructure and a vertical separation). But these authors are not certain these improvements will be replicated following a similar form of restructuring in transition economies, especially if one takes account of the much higher shadow price on the government subsidies in the latter cases.

For the purposes of our study, it is important to analyze the reasons for the absence of reforms and the restructuring of the Chinese railway which are suggested by Min and Jie (2009). In this paper, the authors explain the issues involved in the China Railway restructuring by considering the conditions, and in the view of the interests of the key stakeholders. These authors believe that the reason for the slow development of the China railway restructuring is a conflict of interests, which is difficult to reconcile, among the key stakeholders, including the central government, the Ministry of Railways and the railway transport enterprises. The problems of the restructuring a national railway, which is essentially a part of the European transport corridor, are described in a work by Gasparik, Peceny, Blaho and Paper that analyzes the proposal for the "Consolidation of rail freight transport in Slovakia" (2013). The main reasons for the internal restructuring of Zeleznicna spolocnost Cargo Slovakia a. s. (ZSSK CARGO) is its high debt load that does not allow for its standard functioning or for the development of the railway operators.

\section{Conclusion}

The formation of the global transport market requires a different strategy for the Russian railways, which have been experiencing a highly competitive environment, primarily in the East-West spaces. As part of the international transport corridors, the Russian railways must meet the requirements of the emerging new technological order, and therefore the industry needs restructuring in order to ensure the growth of transport competitiveness and significant investments for the infrastructure development. In this paper, we have presented the results of a study about the consequences of privatization and the restructuring of railways throughout the world and in the Russian Federation. The arguments from the supporters of "unconditional" privatization are not supported by either corresponding policies or practices. The effectiveness of privatization is a higher quality of public administration and a better quality of the market. However, the poor quality of the state management cannot be seen as a decisive argument in favor of privatization, as it also leads to high transformation costs and coexists with a low market quality. This explains the negative impact of privatization on the efficiency of the transport companies and overall economic growth in the developing countries. Thus, decisions about privatization should be considered in the context of the more general task of seeking a rational ownership structure in the economy. The main issues involved in the industry development and the problems with the growth of the value of railway assets should be solved with regard to the OJSC «Russian Railways» and to the entire Russian market for railway transport services. Firstly, there must be a logical conclusion of the railway reforms not only with respect to the business structure, but also concerning the most important economic activities, such as the long-term tariffs, the introduction of a network infrastructure contract, and an institutional capacity to improve competitiveness. Secondly, the future status of the railway companies must be clearly defined, and the potential losses resulting from the 


\section{Managerial Challenges in Russian Railways Privatization and Restructuring}

in the Context of Integration into Global Transport Systems

Author: Natalia Aleksandrovna Zhuravleva

privatization and restructuring must be estimated. An effective industry model should be the basis for the integration of the industry into global transport systems, while reflecting the requirements of spatial and temporal efficiency. Concerning new investments in a high-speed rail infrastructure for international rail transport, it can be assumed that the long payback periods for such a project will be asymmetrical to the privatization of the railways. The confirmation or refutation of this conclusion will subject to a subsequent study by the author.

\section{References}

Asquer, A. (2011). Liberalization and regulatory reform of network industries: A comparative analysis of Italian public utilities, Utilities Policy, 19(3), 172-184.

Baaj, M.H. (2002). Restructuring the Lebanese Railway and Public Transport Authority (RPTA): from losing operator to effective regulator, Transport Reviews, 22(1), 103-113.

Boardman A.E., Claude L. \& Vining A.R. (2002). Privatization in Canada: Operating and stock price performance with international comparisons. Canadian Journal of Administrative Sciences, 19(2), 137-154.

Cavaliere A. \& Scabrosetti S. (2008). Privatization and efficiency: From principals and agents to political economy. Journal of Economic Surveys, 22(4), 685-710.

D’Souza J. \& Megginson W. (1999). The financial and operating performance of privatized firms during the 1990s. Journal of Finance, 54(4), 1397-1438.

Estache, A., Gonzalez, M. \& Trujillo, L. (2002). What does "privatization" do for efficiency? Evidence from Argentina's and Brazil's railways, World Development, 30(11), 1885-1897.

Evans, A.W. (2010). Rail safety and rail privatisation in Japan, Accident Analysis and Prevention, 42(4), 12961301.

Evans, A.W. (2013). The economics of railway safety, Research in Transportation Economics, 43, 137-147.

Friebel, G., Guriev, S., Pittman, R., Shevyakhova, E. \& Tomova, A. (May 2007). Railroad restructuring in Russia and Central and Eastern Europe: One solution for all problems? Transport Reviews, 27(3), 251-271.

Gasparik, J., Peceny, L. \& Blaho, P. (2013). Regulated and unregulated competition on rails. Telc. Restructuralization and Consolidation of the Railway Company Cargo Slovakia, CORP, 40-48.

Gibb, R., Lowndes, T. \& Charlton, C. (1996). The Privatization of British rail. Applied Geography, 16(1), $35-51$.

Kessides, I.N. (2005). Infrastructure privatization and regulation: Promises and perils, World Bank Research Observer, 20(1), 81-108.

Kole S.R. \& Mulherin J.H. (1997). The government as a shareholder: A case from the United States. Journal of Law and Economics, XL.

Lust, A. (2017). Broken rails: The privatisation of Estonian railways, Post-Communist Economies, 29(1), 71-89.

McCartney, S. \& Stittle, J. (2008). 'Taken for a Ride': The privatization of the UK railway rolling stock industry, Public Money \& Management, 28(2), 93-100.

Min, S. \& Jie, D.A. (2009). China railway restructuring: Analysis of the reasons for slow development. International Conference on Public Economics and Management ICPEM, 6, 465-469.

Mwase, N. (2003). The liberalisation, de-regulation and privatisation of the transport sector in sub-Saharan Africa: Experiences, challenges and opportunities, Journal of African Economies, 12, 153-192.

Parker, D. (2013). The privatized railways: problems foreseen, Public Money \& Management, 33(5), 313-319.

Pelaez, A.L., \& Sanchez-Cabezudo, S.S. (2010). Privatization policies or degradation policies? The case of Spanish railways, Revista Internacional de Sociologia, 68(3), 757-773.

Pendleton, A. (2003). Does privatization create a 'new breed' of managers? A study of the UK railway industry, Human Relations, 56(1), 85-111.

Pittman, R. (2011). Risk-averse restructuring of freight railways in China. Utilities Policy, 19(3), 152-160.

Pollitt, M.G. \& Smith, A.S.J. (Dec. 2002). The restructuring and privatisation of British rail: was it really that bad. Fiscal Studies, 23(4), 463-502.

Polterovich V. (2012). Privatization and the rational ownership structure. Part 1. Privatization: the efficiency problem. Economic Science of Modern Russia, 4(59), 7-23.

Russian railways (2017). Рейтинги. [Online]. Available: http://ir.rzd.ru/static/public/ru?STRUCTURE_ID=43 дата обращения 14.11.2017.

Sappington D.E.M. \& Stiglitz J.E. (1987). Privatization, information and incentives. Journal of Policy Analysis and Management, 6(4), 567-582.

Shaoul, J. (2006). The cost of operating Britain's privatized railways, Public Money \& Management, 26(3), 151158. 
Shapiro C. \& Willig R.D. (1990). Economic rationales for the scope of privatization E.N. Suleiman and J. Waterbury (Eds.). The Political Economy of Private Sector Reform and Privatization. Boulder, CO: Westview Press.

Shavshukov V.M. (2016). BRICS at Global Debt Capital Markets (2005-2015). 16 $6^{\text {th }}$ International Scientific Conference on Globalization and its Socio-Economic Consequences. Zilina, Slovak Republic, 1996-2004.

Straska M. \& Waller G. (2012). Does investment improve when firms go private? Managerial Finance, 38(2), 124-142.

Taylor, Z. (2004). Recent changes in Polish transport policy, Transport Reviews, 24(1), 19-32.

The Growth Report Strategies for Sustained Growth and Inclusive Development. (2009). Commission on Growth and Development, 19-20.

Thompson, L. (2003). Changing railway structure and ownership: is anything working? Transport Reviews, 23(3), 311-355.

Tovar, B. \& Martin-Cejas, R.R. (2010). Technical efficiency and productivity changes in Spanish airports: A parametric distance functions approach, Transportation Research Part E-Logistics and Transportation Review, 46(2), 249-260.

Villalonga B. (2000). Privatization and Efficiency: Differentiating Ownership Effects from Political, Organizational and Dynamic Effects. Journal of Economic Behavior \& Organization, 42, 43-74.

Watson, R. (2001). The effect of railway privatization on train planning: a case study of the UK, Transport Reviews, 21(2), 181-193.

Wolf, W. (2017). The railways in the storm of privatization in. Europe and Germany, Ponte, 73(10), 56-69.

Zhuravleva N.A. \& Panichev A.U. (2016). Megatrends of Global Transportation Systems Development in the Russian Segment. $16^{\text {th }}$ International Scientific Conference on Globalization and its Socio-Economic Consequences, University of Zilina, The Faculty of Operation and Economics of Transport and Communications, Department of Economics. Rajecke Teplice, Slovak Republic, 2505-2515. 